\title{
Experimental investigation of polymer flooding with low-salinity preconditioning of high temperature-high-salinity carbonate reservoir
}

\author{
Umar Alfazazi ${ }^{1} \cdot$ Waleed AlAmeri ${ }^{1} \cdot$ Muhammad R. Hashmet $^{2}$
}

Received: 10 May 2018 / Accepted: 5 October 2018 / Published online: 12 October 2018

(c) The Author(s) 2018

\begin{abstract}
Application of polymer flooding in high temperature-high salinity (HTHS) carbonate reservoirs is challenging due to lack of polymers that can withstand such harsh reservoir conditions. The traditional polymers are usually sensitive to high salinity, especially at high temperature. However, injection of low-salinity make-up brines may precondition high-salinity reservoirs before initiating polymer flooding which may reduce chemical degradation of polymer. This study aims to evaluate the effectiveness of a partially hydrolyzed polyacrylamide base polymer for mobility control application in a low-salinity preconditioned carbonate reservoir and hence on the improvement of oil recovery at HTHS carbonate reservoir. Core flooding experiments using unsteady-state technique were conducted on reservoir cores with permeability range of 10-100 $\mathrm{mD}$. During each experiments, salinity of the make-up brines were changed to study the effect of preflush salinity and polymer flooding in HTHS reservoir. Oil production from water flooding for all the cases was found to be between 49 and $65 \%$. Polymer helped to reduce the mobility ratio from 4.1 to less than 1 and additional $7-11 \%$ of oil was recovered from the remaining oil saturation after water flooding. Comparisons were also made between oil recovery results based on volumetric production and in situ saturation monitoring (ISSM) data, which were found to be matching. Additionally, the ISSM helped to understand the performances of fluids injected during oil recovery stages and captured front movement of the fluids at all time. Also, high capillary end effect was confirmed from the ISSM which may lead to underestimation of the oil recovery from water flooding in the absence of ISSM. Resistance factor and residual resistance factor were also calculated during all core flooding experiments and were found to be 7.0, 2.4, 36 and 3.7, 1.4, 8.9, respectively.
\end{abstract}

Keywords Polymer flooding $\cdot$ HPAM $\cdot$ IOR $\cdot$ X-ray scanning $\cdot$ In situ saturation monitoring $\cdot$ Carbonate reservoir $\cdot$ HTHS · Low salinity water flooding

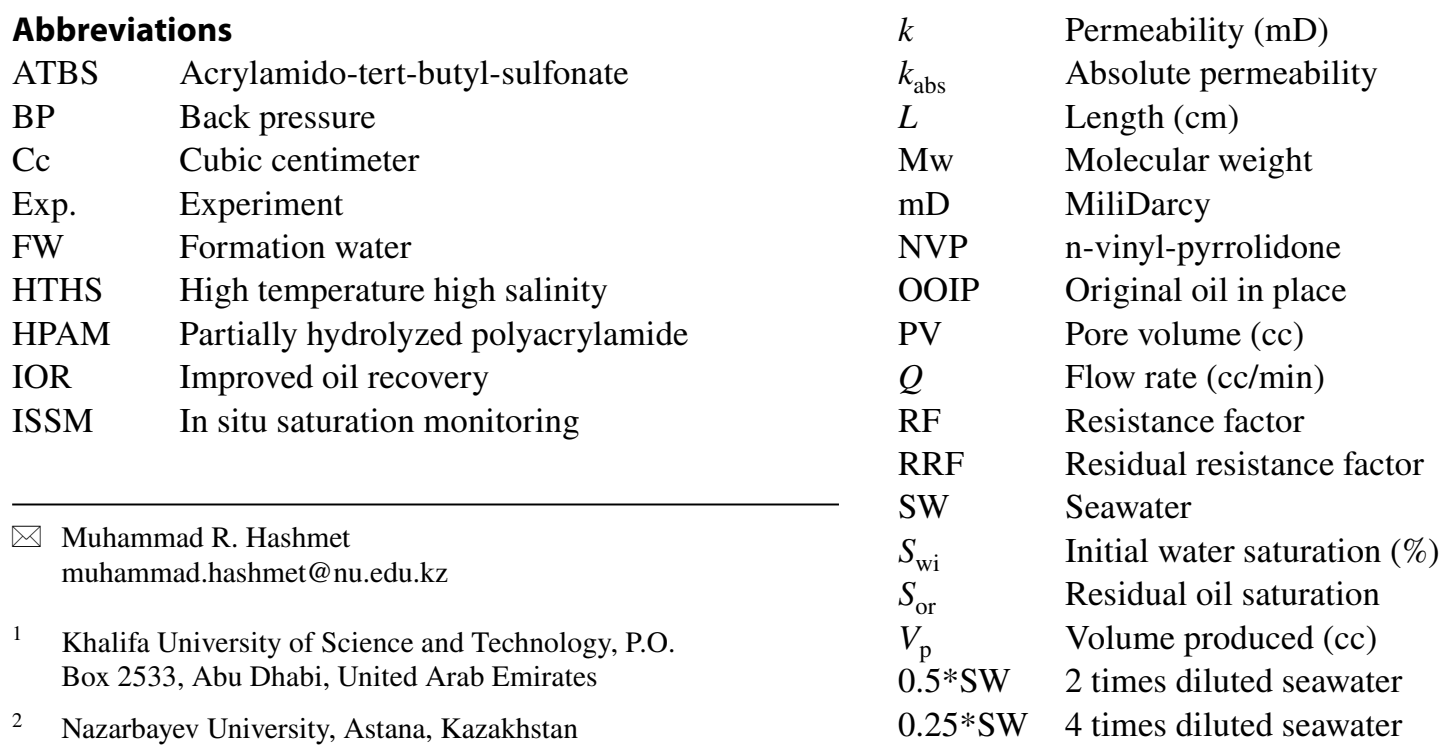




$\begin{array}{ll}\mu & \text { Viscosity (cP) } \\ \Delta P & \text { Differential pressure (psi) } \\ \rho & \text { Density (g/cc) }\end{array}$

\section{Introduction}

Polymer flooding is considered as one of the most successful IOR techniques with over 40 years of application, both in lab and field scale. The main objective of polymer flooding is to increase the viscosity of injection water to improve mobility ratio of oil and water (Samanta et al. 2010). This is achieved by addition of water soluble polymers to the injection water (Gaillard et al. 2014; Salmo et al. 2017). In most cases, an unfavorable mobility ratio exists in the reservoir during water flooding due to the high viscosity of oil compared to water. This results in high water production (Khorsandi et al. 2016) whereas a significant portion of the oil is left within the pores (Zhang et al. 2011). Previous studies (Algharaib et al. 2014) have shown that polymer flooding technique can improve oil recovery by $10-15 \%$ from remaining oil saturation after water flooding.

Most of the field applications where polymer flooding is practiced are sandstone reservoirs. The temperature of such reservoirs usually does not exceed $65^{\circ} \mathrm{C}$ (Delaplace et al. 2013; Wang et al. 2008). Hence, its application beyond this temperature becomes difficult (Gao 2013) due to the unavailability of polymers that withstands such conditions. This complexity increases especially in carbonate reservoirs. Although, polymer flooding is believed to have the potential to improve oil recovery from carbonate reservoirs based on the current ongoing research (Bennetzen et al. 2014; Gaillard et al. 2014; Quadri et al. 2015; Vermolen et al. 2011). The complex nature of carbonate reservoirs as well as their high formation water salinity and high temperature $\left(\sim 170,000 \mathrm{ppm}\right.$ and $\left.\sim 120^{\circ} \mathrm{C}\right)$, especially in the Middle Eastern region, makes it difficult to find suitable polymer candidates to implement this IOR technique. In addition, performance of polymer flooding is majorly dependent on reservoir heterogeneity, salinity, temperature, permeability and its compatibility with other chemicals use for oil recovery (Almansour et al. 2017; Hashmet et al. 2017a; Sheng 2017).

There are mainly two types of polymers used for oil recovery purposes: synthetic partially hydrolyzed polyacrylamide HPAM (and its derivatives) and biopolymer such as Xanthan (Sheng et al. 2015). HPAMs are the most widely used polymers for IOR applications compared to the biopolymers (Samanta et al. 2010; Sorbie 2013). However, these polymers tends to degrade or hydrolyze under harsh conditions especially in the presence of high salinity (Green and Willhite 1998). On the other hand, Xanthan biopolymer is capable of resisting very high salinity conditions
(Cannella et al. 1988; Sheng et al. 2015). The main problems associated with this polymer is poor injectivity and biodegradation which makes the HPAMs more preferable for IOR applications (Hashmet et al. 2017a; Seright et al. 2011; Unsal et al. 2018; Zaitoun et al. 2012). Although, the viscosifying properties of all HPAM base polymers strongly depend on brine salinity given their polyelectrolyte character (Khorsandi et al. 2017; Nasr-El-Din and Taylor 1996). In severe conditions, especially in the cases of carbonate reservoirs, use of more robust polymers are necessary to ensure the stability of the polymers in reservoirs for a long period (Gaillard et al. 2015; Han et al. 2012).

In recent years, efforts have been made by researchers to discover new types of polymers that can withstand HTHS (Bennetzen et al. 2014; Gaillard et al. 2015; Leblanc et al. 2015; Levitt et al. 2013). This development was achieved by the incorporation of some specific monomers such as acrylamido-tert-butyl-sulfonate (ATBS) or N-vinyl-pyrrolidone (NVP) to the backbone chain of the polymers thereby, adding more stability (by limiting hydrolysis) and robustness to the polymer especially at high temperature (Vermolen et al. 2011). Depending on the level of these monomers at the polymer backbone chain, such polymers can withstand very high salinity and high temperature (Gaillard et al. 2014; Vermolen et al. 2011).

The effectiveness of these types of polymers can be further enhanced by preconditioning the reservoir through injection of low-salinity brines (preflush) before polymer flooding, thus reducing chemical degradation. In addition, viscosity of HPAM base polymers always increases as the salinity of the water is lowered which is caused by the polymer expansion and electrostatic repulsion (Unsal et al. 2018; Vermolen et al. 2014; Wever et al. 2011). This also means that lower concentration of polymer would be required to reach a target viscosity compared to when the polymer is prepared in high salinity brine (Algharaib et al. 2014; Vermolen et al. 2014). Also, injection of low-salinity brines before polymer flooding could also lead to additional oil recovery by changing the rock wettability to a more water-wet condition (Almansour et al. 2017; RezaeiDoust et al. 2011; Shaker and Skauge 2013), although, its success strongly depends on rock mineralogy as well as fluid properties.

Algharaib et al. (2014) investigated the effect of polymer concentration on the performance of polymer flooding in high salinity reservoirs. They reported that there are limits of concentration above which polymer performance decreases. They also studied the effect of polymer slug size on oil recovery which they concluded that for each formation or reservoir conditions, there is an optimum slug size and concentration required for polymer flooding. In addition, they found out that at high salinity, the performance of the polymer reduces. Similar experiments were also conducted 
to study polymers for chemical flooding in carbonate reservoirs characterized with high salinity and high temperature. The target of the study was a representative carbonate reservoir in the Middle East. Finally, they reported that an additional oil recovery by polymer flooding was about $11 \%$ with a $3000 \mathrm{ppm}$ sulfonated polyacrylamide which was injected at the tertiary recovery stage and under reservoir conditions (Han et al. 2014).

In this study, an NVP-HPAM base polymer (SAV10) was used to conduct oil recovery experiments. It is a terpolymer made of N-vinyl-pyrrolidone (NVP) which gives it ability to resist high temperature and salinity. In addition, oil recovery studies were carried out on a linear X-ray core flood system which helps in monitoring the in situ fluids saturation in addition to the pressure and volumetric production data. The linear X-ray data were automatically recorded by the system in terms of counts along the core length and later converted to saturations. This is an advanced technology that gives better understanding of fluids performances as well as level of capillary end effect. Core flood experiments were also conducted by Hashmet et al. (2017b) to study the effectiveness of a HPAM base polymer on oil recovery in HTHS carbonate reservoirs. Results of the experiments showed that the polymer was effective in enhancing the mobility ratio and was able to produce more oil (Hashmet et al. 2017b). The experiments were conducted with the aid of a linear X-ray core flood system to record the ISSM data. They concluded that the ISSM data helped in understanding the fluids efficiency, as well as fluid distribution along the core. In this study, the impact of low-salinity polymer flooding is investigated on HTHS carbonate reservoir cores.

\section{Materials and methods}

Materials used in this study include four synthetic brines, high viscosity lab oil (Primol 352), crude oil, 1-iododecane, SAV10 polymer, and three carbonate reservoir cores samples from a Middle Eastern field. The brines were prepared in the lab by mixing exact amount of salts with deionized water. They include formation water (FW), seawater (SW), 2 times diluted seawater $\left(0.5^{*} \mathrm{SW}\right)$, and 4 times diluted seawater $\left(0.25^{*} \mathrm{SW}\right)$. FW of $167,000 \mathrm{ppm}$ salinity was prepared based on the composition of the target reservoir. While SW with salinity of $39,000 \mathrm{ppm}$ was prepared based on the seawater salt composition. Finally, $0.5 * \mathrm{SW}(19,500 \mathrm{ppm})$ and $0.25 * \mathrm{SW}(9750 \mathrm{ppm})$ were prepared by simple dilution of SW with deionized water twice and four times respectively. Table 1 provides the composition of brines used in this study. Due to the presence of water molecules in $\mathrm{CaCl}_{2}$ and $\mathrm{MgCl}_{2}$, a calculated amount of the same salts was added to the brines to compensate for the water molecules.
Table 1 Composition of synthetic brines

\begin{tabular}{lcccl}
\hline Salts & $\begin{array}{l}\text { Formation } \\
\text { water }(\mathrm{FW}) \\
(\mathrm{g} / \mathrm{L})\end{array}$ & $\begin{array}{l}\text { Seawater } \\
(\mathrm{SW})(\mathrm{g} / \mathrm{L})\end{array}$ & $\begin{array}{l}0.5^{*} \mathrm{SW} \\
(\mathrm{g} / \mathrm{L})\end{array}$ & $\begin{array}{l}0.25^{*} \mathrm{SW} \\
(\mathrm{g} / \mathrm{L})\end{array}$ \\
\hline $\mathrm{NaCl}$ & 134.61 & 24.80 & 12.40 & 6.20 \\
$\mathrm{KCl}$ & 1.42 & 0.80 & 0.40 & 0.20 \\
$\mathrm{CaCl}_{2} \cdot 2 \mathrm{H}_{2} \mathrm{O}$ & 33.93 & 2.11 & 1.06 & 0.53 \\
$\mathrm{MgCl}_{2} \cdot 6 \mathrm{H}_{2} \mathrm{O}$ & 12.10 & 25.17 & 12.59 & 6.29 \\
\hline
\end{tabular}

Table 2 Petrophysical properties of core samples used for oil recovery studies

\begin{tabular}{lrrr}
\hline Core ID & Exp. 1 & Exp. 2 & Exp. 3 \\
\hline Length $(\mathrm{cm})$ & 7.34 & 6.96 & 7.06 \\
Porosity $(\%)$ & 27.73 & 27.14 & 27.94 \\
Pore volume (cc) & 23.45 & 22.69 & 22.72 \\
Air permeability (mD) & 35.26 & 130.14 & 15.29 \\
Absolute permeability (mD) & 27.00 & 94.00 & 10.00 \\
\hline
\end{tabular}

High viscosity lab oil was used to reach reservoir representative initial water saturation, $S_{\mathrm{wi}}$ before switching to crude oil. The crude oil was initially filtered with a filter paper $(0.45 \mu \mathrm{L})$ to remove asphaltenes and unwanted solid deposits before usage. SAV10 which is HPAM base polymer was used for conducting this study and was provided by SNF FLOERGER in powder form. The molecular weight (Mw) of the polymer was reported to be 2-4 million Daltons. In addition, the polymer solutions were prepared in accordance with the API standards for polymer preparation (API R 63 1990). All solutions were prepared in the glove box so as to maintain minimum oxygen level $(0.5 \mathrm{ppm})$ in the solutions. Initially, the prepared brines were transferred into the glove box and stirred for $30 \mathrm{~min}$ to get rid of oxygen in the brines. Then, the brines were stirred on a magnetic stirrer at high speed of $300 \mathrm{rpm}$ with the vortex extending to about $70 \%$. The polymer powder was then sprinkled gently on the shoulder of the vortex to avoid agglomeration of polymer. The speed of the stirrer was reduced to $100 \mathrm{rpm}$ after $10 \mathrm{~min}$ of fast stirring to avoid mechanical degradation. Finally, the solutions were left overnight on the stirrer to completely homogenize.

Three reservoir core samples with diameter of $3.8 \mathrm{~cm}$ each were used to conduct core flood experiments. Core plugs were first cleaned thoroughly with multiple solvents to remove reservoir crude oil and unwanted chemicals before usage. Then, basic routine core analysis which includes dry weight, porosity, permeability, and wet (saturated) weight measurements were conducted. Even though, the cores were all from the same field and similar depth, the permeabilities 
varies. Table 2 presents the petrophysical properties of core samples used in this study.

\section{Core flooding experiments}

Three sets of unsteady state core flood experiments were conducted to evaluate the impact of water flood and polymer on oil recovery at reservoir condition (high temperature, pressure, and salinity). In addition to the pressure and volumetric production data, the core flood equipment (shown in Fig. 1) is also coupled with linear X-ray which helps in monitoring the in situ saturation profiles in real time. The system automatically records its data in counts and can be converted to real-time in situ saturations with the aid of a simple formula (Eq. 1). The core flood system consists mainly of a core holder, three fluid accumulators, injection pumps, and pressure transducers. In addition, a computer is also connected to the equipment and is used for monitoring and recording parameters such as temperature, flow rates, pressures, and counts.

Saturation $=\frac{\log (\text { selected scan })-\log (100 \% \text { oil })}{\log (100 \% \text { water })-\log (100 \% \text { oil })}$

It is important to note that, one of the injected fluids is required to be doped (this could be either brine or oil) to differentiate the fluids calibrations in the linear X-ray data. As such, the doped fluid shows lesser counts while the undoped fluid shows higher counts. However, without doping one of the phases, the fluids show the same trend and hence it becomes difficult to understand the performance of each fluid during the injection process. In this study, crude oil was doped by adding $10 \%$ of 1 -iododecane to the crude oil. To capture the complete saturation profile during both drainage and imbibition, it is necessary to follow certain procedure.

First, a clean-dry core plug is $100 \%$ saturated (by vacuum) with the doped crude oil and later flooded in the core flood system at reservoir temperature and pressure. Several X-ray scans are recorded to represent $100 \%$ oil saturation. The core is then re-cleaned with solvents and dried by following the standard procedure. The core is then saturated with FW to determine brine absolute permeability and scan to represent $100 \%$ water saturation. Absolute permeability is determined by injecting formation brine at different flow rates. Based on the differential pressures at each flow rate, absolute permeability is calculated from Darcy's law as shown in (Eq. 2). Drainage experiment is then initiated to reach initial water saturation $S_{\mathrm{wi}}$. Similarly, several scans are recorded, the last scan is considered as the $S_{\mathrm{wi}}$. To reach $S_{\mathrm{wi}}$, Primol followed by crude oil are injected at different flow rates until water production from the core is negligible and steady state conditions are achieved. $S_{\mathrm{wi}}$ is calculated with the help of (Eq. 3). The core is then aged for 1 month to restore reservoir conditions and wettability (Shaker and Skauge 2013). Oil effective permeability is re-calculated after ageing and to account for any change in $S_{\text {wi }}$. Imbibition is then initiated afterwards by injecting brine(s) followed by polymer (in accordance with the injection scenarios). In the process, X-ray scan is constantly monitoring the fluids saturations as fluids injection and displacement is taking place. It is important to state that, the above steps and experiments are all conducted at $120^{\circ} \mathrm{C}$ and back pressure (BP) of $750 \mathrm{psi}$ to mimic the reservoir conditions. To summarize the procedures

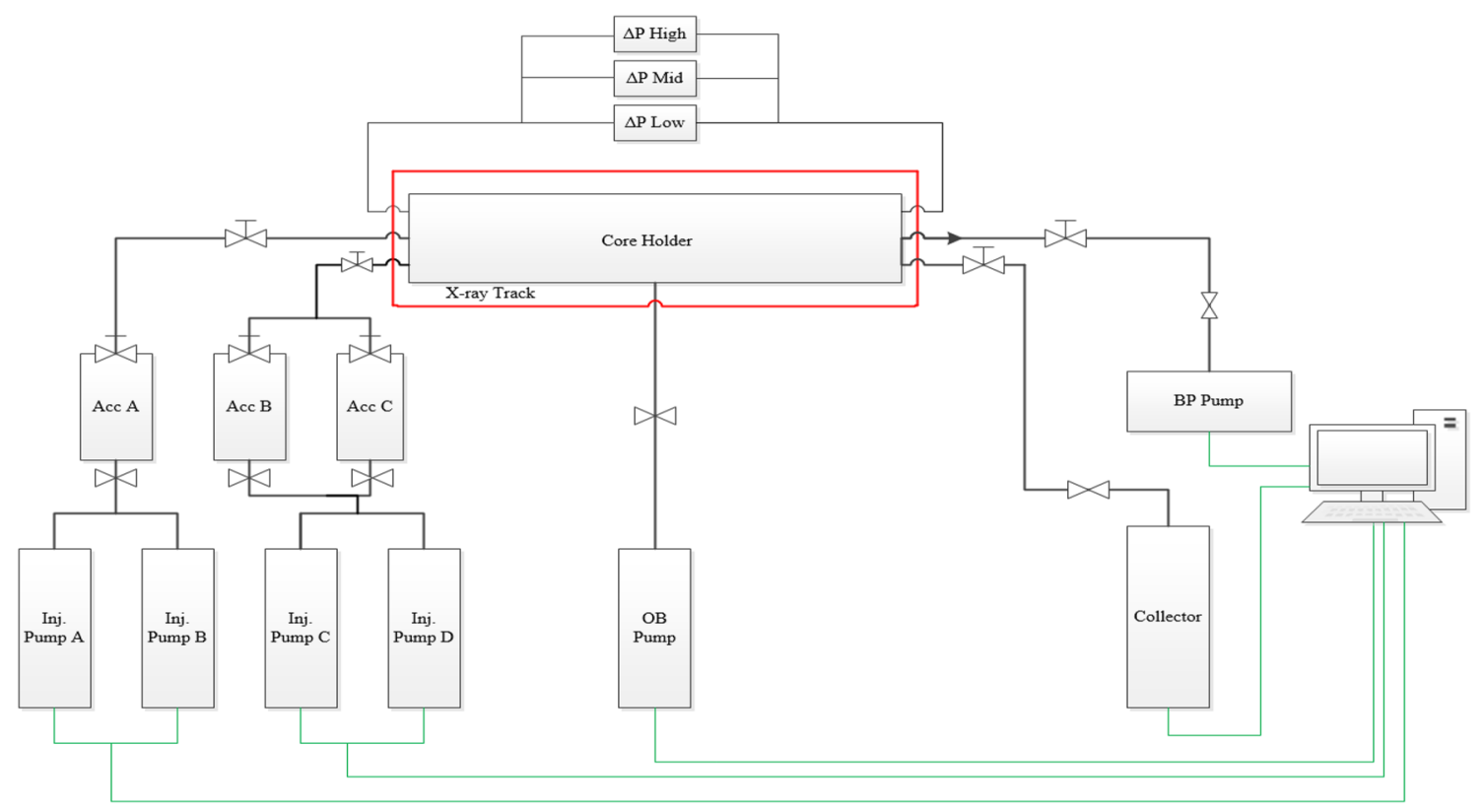

Fig. 1 Schematic of linear X-ray core flood equipment (LXRCF) used for conducting core flood experiments 
described above, each core flooding experiment is made up of six phases and these are shown in Fig. 2.

$k_{\mathrm{abs}}=\frac{14700 * \mu * Q * L}{A * \Delta \mathrm{P}}$

$S_{\mathrm{wi}}=\left(1-\frac{V_{p}}{P V}\right) \times 100 \%$

The following injection scenarios were followed during the core flood experiments: seawater was initially injected in all the three core floods until steady state conditions were achieved during water flooding. Then, in 1st core flooding (Exp. 1), polymer flooding was initiated immediately after SW flooding and was followed by SW postflush. In the 2nd experiment (Exp. 2), $0.5 * \mathrm{SW}$ was injected after SW flooding and prior to polymer flooding to evaluate the effect of low-salinity water flooding preflush on oil recovery. While in the 3rd core flooding experiment (Exp. 3), $0.25^{*} \mathrm{SW}$ was injected after SW flooding, later followed by polymer flooding and post flush. During polymer flooding and postflush, major parameters such as resistance factor $(\mathrm{RF})$ and residual resistance factor (RRF), are calculated from the following equations respectively

$\mathrm{RF}=\frac{\left(\frac{k}{\mu}\right)_{\text {brine }}}{\left(\frac{k}{\mu}\right)_{\text {polymer }}}=\frac{\Delta \mathrm{P}_{\text {polymer }}}{\Delta \mathrm{P}_{\text {brine }}}$

Fig. 2 Core flood procedure for oil recovery studies
$\mathrm{RRF}=\frac{\left(\frac{k}{\mu}\right)_{\text {brine preflush }}}{\left(\frac{k}{\mu}\right)_{\text {brine post flush }}}=\frac{\Delta \mathrm{P}_{\text {brine postflush }}}{\Delta \mathrm{P}_{\text {brine preflush }}}$

\section{Results and discussions}

\section{Fluids properties}

Viscosity and density measurements of fluids were done with the aid of viscometer and densitometer. Table 3 enlists the properties of the fluids used at different temperatures. As for the polymer solutions, three solutions were prepared based on the injection scenarios. In the 1st core flood, the polymer was prepared in SW because the same brine was used during preflush. Likewise, in the 2 nd and 3rd core flood experiment, the polymers were prepared in $0.5^{*} \mathrm{SW}$ and $0.25^{*} \mathrm{SW}$, respectively.

Polymer concentration was considered during polymer preparation to control the viscosity at the experimental condition. The condition was that; the polymer solutions should have viscosity close to the oil viscosity $(1.2 \mathrm{cP})$ at $120{ }^{\circ} \mathrm{C}$ from the rheometer. Based on the series of rheological tests carried out, $3000 \mathrm{ppm}$ was selected as the optimum concentration for the core flooding. The rheology measurements were conducted with the aid of a stress controlled shear rheometer HR-3 (by Anton Paar). In addition,
Table 3 Density and viscosity measurements of fluids at different temperatures

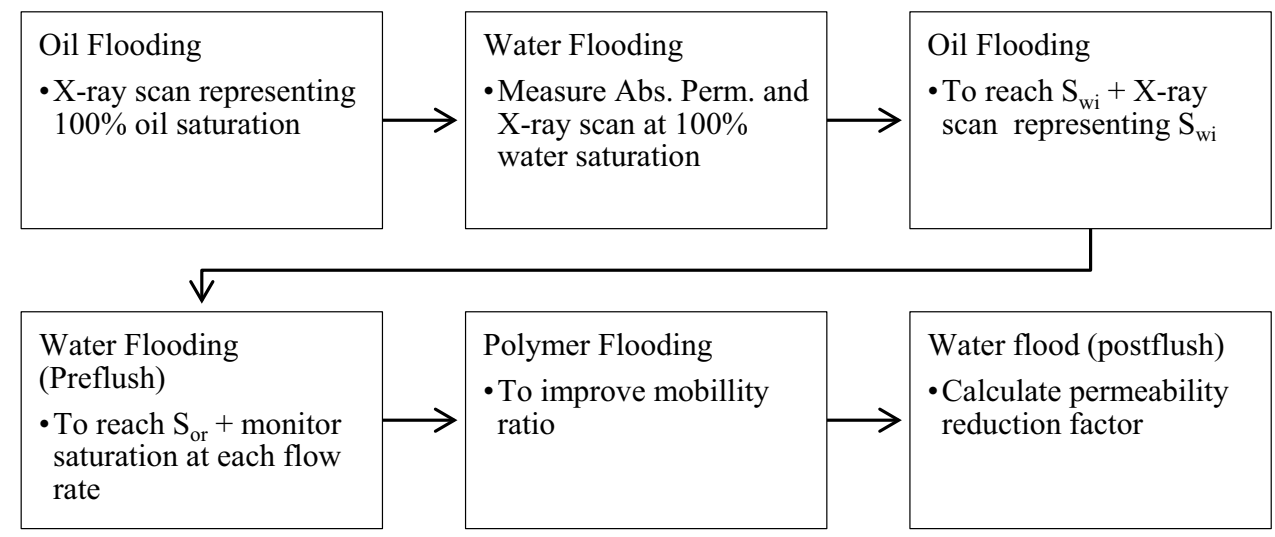

\begin{tabular}{llllllll}
\hline Brines & \multicolumn{2}{l}{ Density, $\rho(\mathrm{g} / \mathrm{cc})$} & & \multicolumn{2}{l}{ Viscosity, $\mu(\mathrm{cP})$} \\
\cline { 2 - 3 } & $T=20{ }^{\circ} \mathrm{C}$ & $T=60{ }^{\circ} \mathrm{C}$ & $T=120{ }^{\circ} \mathrm{C}$ & & $T=20{ }^{\circ} \mathrm{C}$ & $T=60{ }^{\circ} \mathrm{C}$ & $T=120{ }^{\circ} \mathrm{C}$ \\
\hline $\mathrm{FW}$ & 1.11 & 1.09 & 1.01 & & 1.69 & 0.82 & 0.45 \\
$\mathrm{SW}$ & 1.02 & 1.01 & 0.84 & & 1.12 & 0.72 & 0.40 \\
$0.5^{*} \mathrm{SW}$ & 1.01 & 0.99 & 0.82 & & 1.10 & 0.72 & 0.38 \\
$0.25^{*} \mathrm{SW}$ & 1.01 & 0.99 & 0.79 & & 1.04 & 0.70 & 0.37 \\
Doped primol & 0.88 & 0.87 & 0.83 & & 62.05 & 19.14 & 4.58 \\
Doped crude oil & 0.87 & 0.85 & 0.81 & & 5.99 & 2.94 & 1.20
\end{tabular}


measurements were conducted at a constant shear rate of $10 \mathrm{~s}^{-1}$ and temperature ramp from 25 to $120^{\circ} \mathrm{C}$. At $120^{\circ} \mathrm{C}$, the viscosity of the polymer in $\mathrm{SW}, 0.5 * \mathrm{SW}$, and $0.25^{*} \mathrm{SW}$ brines were measured as $0.95,1.09,1.10 \mathrm{cP}$, respectively.

\section{Core flooding results}

\section{Core flooding experiment 1 (Exp. 1)}

As mentioned previously, the core was initially saturated with crude oil to get the $100 \%$ oil scan. The average X-ray counts recorded along the length of the core for complete oil saturated core was 33,876. After re-cleaning the core, absolute permeability was measured by injecting FW at different flow rates and was calculated as $27 \mathrm{mD}$. The average counts from $\mathrm{X}$-ray along the length of core for $100 \%$ water-saturated core was 62,828 . Drainage was then initiated and $S_{\mathrm{wi}}$ was calculated as $11.71 \%$. Also, the average counts from the X-ray at $S_{\mathrm{wi}}$ was 36,507 .

Seawater flooding was then initiated for $23 \mathrm{~h}$ at different flow rates (with $0.2 \mathrm{cc} / \mathrm{min}$ set as the base flow rate) until steady state conditions were achieved and oil production was negligible. The oil production was continuously monitored throughout seawater flooding. Interestingly, an early water breakthrough occurred after $14.5 \%$ production of OOIP (exactly after $15 \mathrm{~min}$ of $\mathrm{SW}$ flooding at $0.2 \mathrm{cc} / \mathrm{min}$ ). This process was fully captured with the help of the ISSM. The early water breakthrough could be as a result of high mobility ratio (calculated as 3.66) which was caused by the large difference in viscosity between the two phase fluids. Also, high permeability channels are expected to have contributed in the early breakthrough, where the injected water follows the easiest paths. Both these factors are common features of carbonate reservoirs.

At the end of seawater flooding, the total oil recovery was calculated to be $51 \%$. Polymer flooding was then initiated afterwards. The viscosity of the polymer solution was 1.2
$\mathrm{cP}$ (from bulk rheology) at $120^{\circ} \mathrm{C}$. Polymer was injected for $16 \mathrm{~h}$ repeating the same flow rates used during water flooding. Polymer flooding helped to improve the mobility ratio to 0.56 and recovered $11 \%$ additional oil from the remaining oil saturation after water flood. However, no additional recovery was recorded during postflush. Figure 3 shows the differential pressure and production (based on volumetric data) from both seawater and polymer flooding.

Based on the differential pressure recorded during polymer flooding and at the end of postflush, resistance factor RF and residual resistance factor RRF were calculated respectively. It can be seen that due to relatively high viscosity of polymer compared to the seawater and also the retention property of polymers on rocks (Agi et al. 2018), the pressure during polymer flooding is high resulting in high resistance factor values (3.72). Figure 4 shows resistance RF and residual resistance factor RRF data as function of flow rates. It was observed that the Resistance factor increases with increasing flow rate, as well as in situ shear rates during polymer flood. The resistance factor at flow rates of 0.2, 0.5, 1.0, and 2.0 (which corresponds with apparent shear rates of 5, 12, 24, and $471 / \mathrm{s}$ ) were calculated as $1.8,2.2,4.5$, and 7.0 respectively. In addition, the effective in situ viscosity during polymer flooding was calculated and was found to be increasing with increasing flow rates (thus, shear thickening behavior). Such behavior is expected above certain critical shear rate as reported by (Seright et al. 2011). This behavior is known as a shear thickening or viscoelastic behavior which is encountered during the injection of HPAM base polymers in porous media (Wei et al. 2014). Research have shown that the elastic properties of such polymers may also reduce the residual oil saturation (Sheng et al. 2015; Vermolen et al. 2011; Wang et al. 2008; Wei et al. 2014). However, this study is out of our scope. As for the residual resistance factor, it was observed that there was a slight decrease with increasing flow rates which can be attributed to decrease in the mechanical entrapment as flow rate is increased during postflush water flooding (AlSofi et al. 2017).
Fig. 3 Oil recovery factor (\%) and differential pressure as a function of PV injected during oil recovery of Exp.1

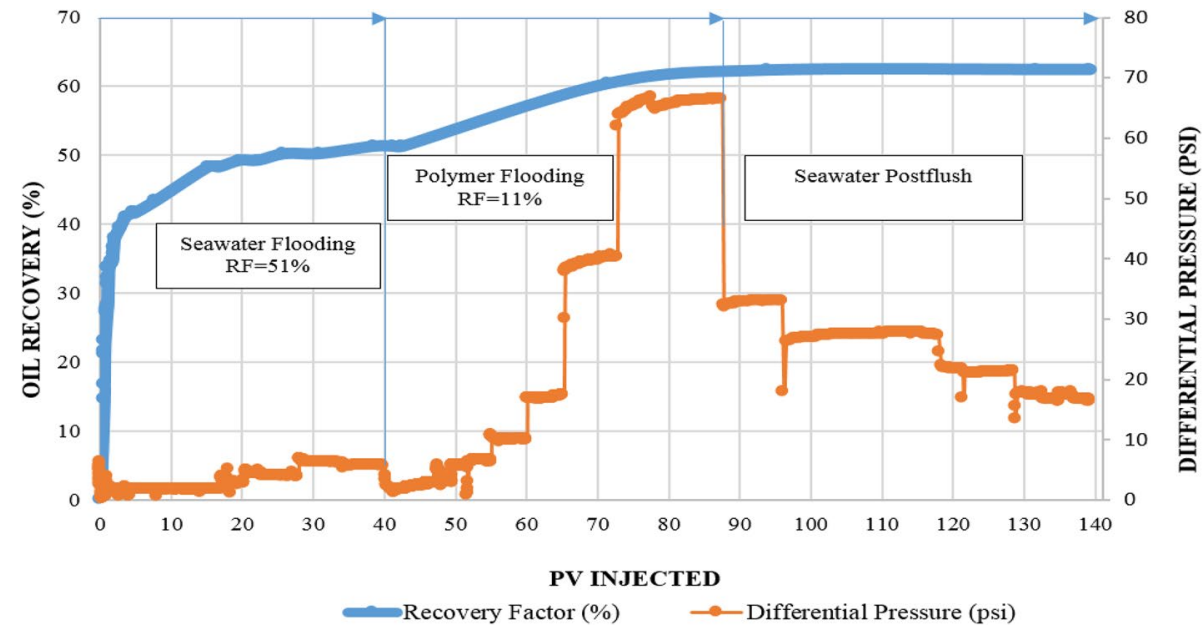


Fig. 4 RF and RRF data as function of flow rates in $\mathrm{cc} / \mathrm{min}$ during Exp.1

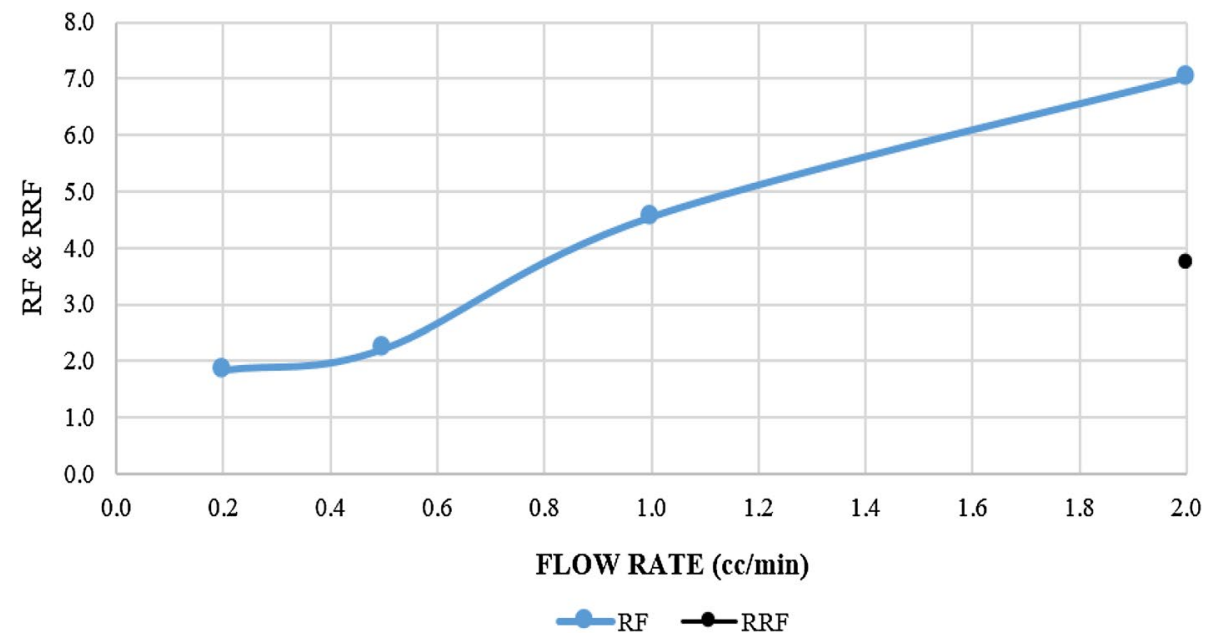

Table 4 Summary of major results from first core flooding experiment

\begin{tabular}{ll}
\hline Core ID & Exp.1 \\
\hline Mobility ratio during WF & 3.66 \\
Mobility ratio during PF & 0.56 \\
Resistance factor RF at $2.0 \mathrm{cc} / \mathrm{min}$ & 7.02 \\
Residual resistance factor RRF at $2.0 \mathrm{cc} / \mathrm{min}$ & 3.72 \\
Water flooding oil recovery (\%) & 51 \\
Additional oil recovery due to polymer (\%) & 11 \\
Total oil recovery (\%) & 62 \\
\hline
\end{tabular}

The apparent shear rate and in situ polymer viscosity were calculated based on the method suggested by (Zaitoun and Kohler 1988). Table 4 summarizes the key results from Exp. 1 .

Based on the ISSM data from the X-ray scans, Fig. 5 shows the complete change in saturation profiles during oil recovery. It showed that water breakthrough has occurred relatively early (the average water saturation at the time of breakthrough was 0.19) which corresponds with the volumetric production data. It also shows that during polymer flooding, the polymer was able to control the mobility ratio and hence increased the sweep efficiency along the length of core. The polymer is promising even with the level of heterogeneity that exist in the core. Comparison was also made between the volumetric production data and the ISSM data to quantify the accuracy of both results. The values appears to be close with difference less than $5 \%$ as shown in Fig. 6. The cumulative oil recovery from volumetric production and in situ saturation was $62 \%$ and $64 \%$, respectively. This margin error is expected from the laboratory data and could be as a result of inaccuracy when taking manual readings (Hashmet et al. 2017b).

The core plug was later CT scanned at residual oil saturation to see the amount of oil left in the core. Figure 7 is the image from the CT scanning. The color variation represents CT numbers in which red color indicates high density which include remaining oil and the rock. Less CT number is representing the water.
Fig. 5 ISSM profile with respect to fluid injected along the core length during Exp.1

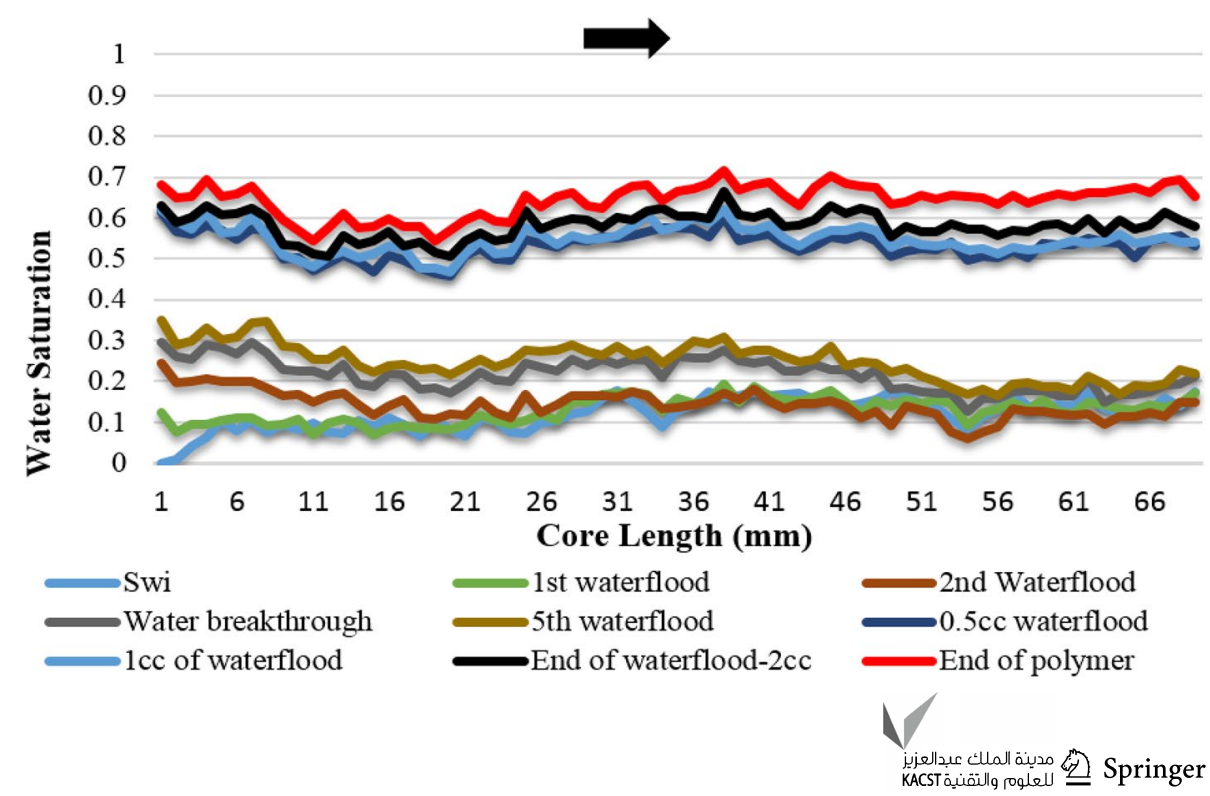


Fig. 6 Comparison between volumetric production data and in situ saturation data during Exp. 1

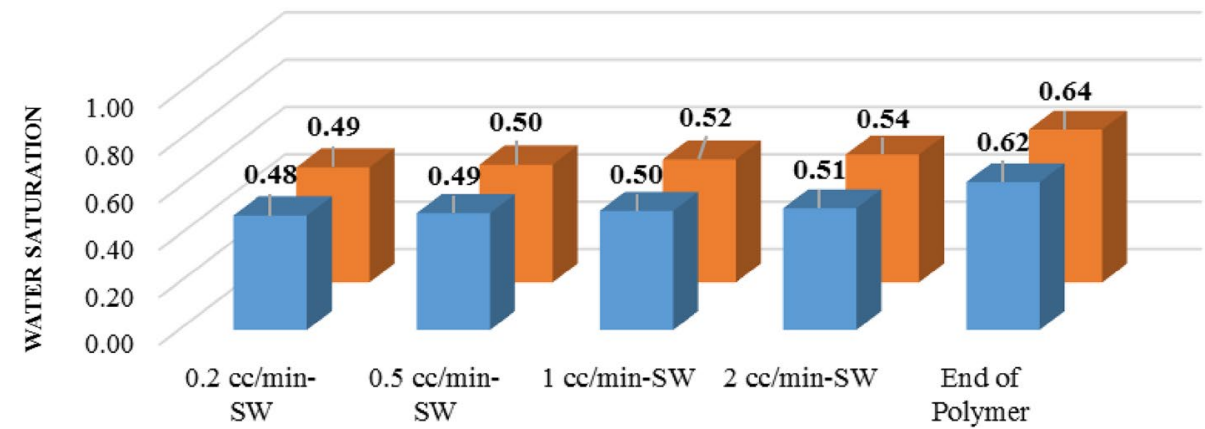

INJECTION SCENARIOS

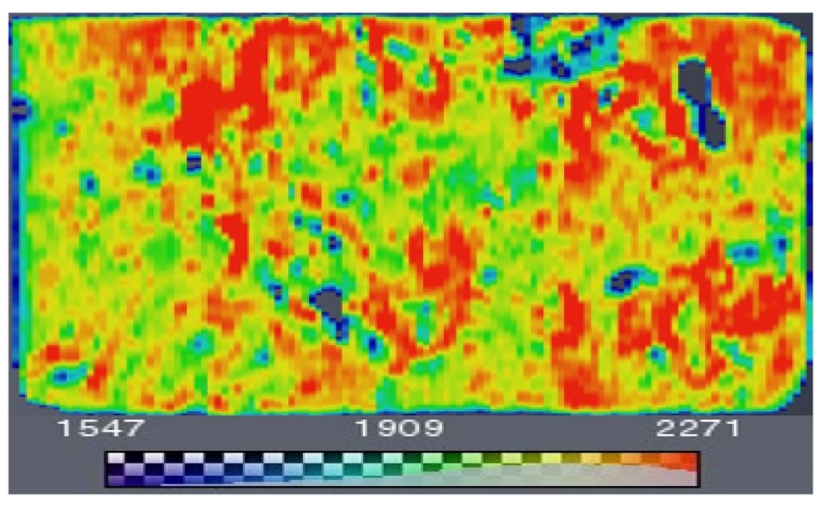

Fig. 7 CT scan image showing high level of heterogeneity and vugs along the length of core

\section{Core flooding experiment 2 (Exp. 2)}

The average counts at the end of oil flooding was 46,650. Then, brine absolute permeability was calculated as $94 \mathrm{mD}$ after injecting several slugs of formation brine at different flow rates. In addition, saturation during brine injection was recorded and the average counts representing $100 \%$ brine saturation was 93,550. During drainage, the $S_{w i}$ was calculated as $14.24 \%$ while the average counts was 51,521 .

Seawater flooding was initially conducted for $40 \mathrm{PV}$ until there is no oil production. Then, the injection fluid was switched to $2 \mathrm{x}$ diluted SW $\left(0.5^{*} \mathrm{SW}\right)$ and injected at the same flow rates as during SW flooding for another 18 $\mathrm{PV}$. The aim was to precondition the core sample to reduce the initial salinity before polymer flooding. In addition, this opportunity was also utilized to see if the low salinity water flooding (by dilution) could possibly increase the oil recovery and hence affect the Sor. Finally, residual resistant factor was calculated after $0.5^{*} \mathrm{SW}$ post flush water flooding.

The cumulative oil recovery during seawater flooding was calculated as $49 \%$. Additional $2 \%$ of oil was recovered from the low salinity water flooding $(0.5 * \mathrm{SW})$. Finally,
$8 \%$ additional oil was recovered by polymer flooding. It is important to state that, the production during low salinity water flooding only occurred during the last flow rate $(2.0 \mathrm{cc} / \mathrm{min})$ and thus, nothing was produced during 0.2 , 0.5 , and $1.0 \mathrm{cc} / \mathrm{min}$. This shows that production during the low salinity water flooding could be due to capillary end effect that was minimized at the highest flow rate. Additional oil recovery during polymer flooding in this particular core flood experiment was expected to be higher as compared to Exp. 1 since low salinity water was used for preconditioning. However, the oil recovery was less and could be due to the heterogeneous nature of core. Figure 8 shows the oil recovery factor (in percent) and differential pressure profile at different stages of fluid injection.

Similarly, the resistance factor was calculated at different flow rates. Interestingly, it was observed that the resistance factor continuously reduces with increasing flow rates. At flow rates of $0.2,0.5,1.0$, and $2.0 \mathrm{cc} / \mathrm{min}$, the resistance factor were calculated as 2.5, 2.0, 2.0, and 1.9, respectively, as shown in Fig. 9. This is as a result of the high effective permeability as well as viscosity reduction (Bennetzen et al. 2014). Also, compared to Exp. 1, the residual resistance factor was lower. This is as a result of low polymer retention due to large pore sizes in high permeability rocks. These results corresponds with the previous literature (Seright et al. 2011, 2008).

The in situ saturation monitoring was also used to understand the performance of each of the fluids injected at different stages of oil recovery. Figure 10 shows the changes in water saturation across the length of the core. At the end of water flooding (SW flooding), the average water saturation was 0.52 . While during low-salinity water flooding, there was a slide change in the saturation during the last flow rate of injection and occurred mainly towards the end of the core. At the end of polymer flooding, there was change in saturation across the length of the core sample even with the high level of heterogeneity which resulted in high capillary end effect. This indicates that the polymer was able to increase the sweep efficiency. It can also be inferred from the ISSM that low 
Fig. 8 Oil recovery factor (\%) and differential pressure vs PV injected during oil recovery of Exp. 2

Fig. $9 \mathrm{RF}$ and RRF data as a function of flow rates in cc/min during Exp. 2
Fig. 10 ISSM profile across the core length showing the changes in water saturation during oil recovery of Exp. 2
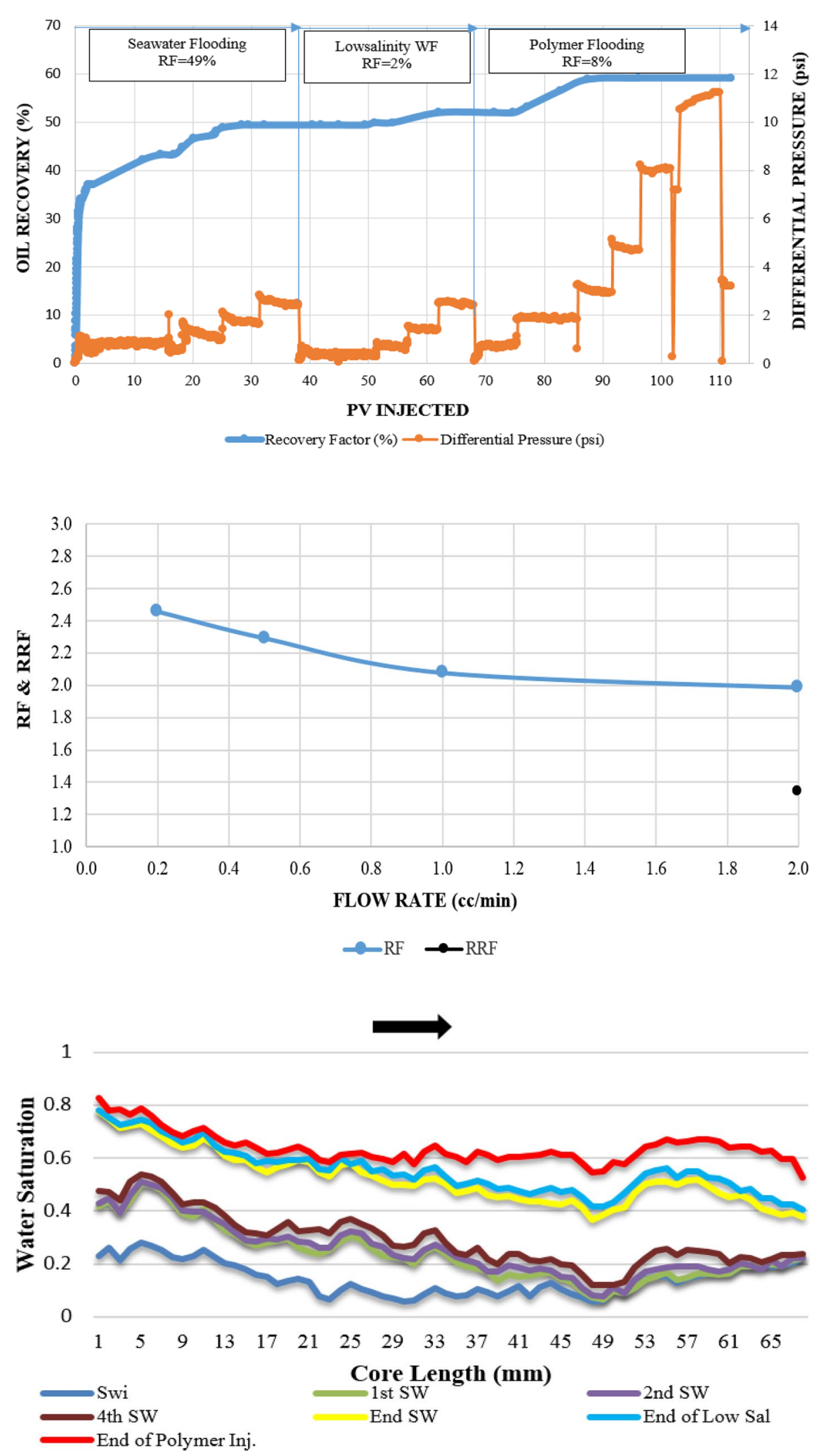
Fig. 11 Comparison between volumetric production data and in situ saturation monitoring during Exp. 2

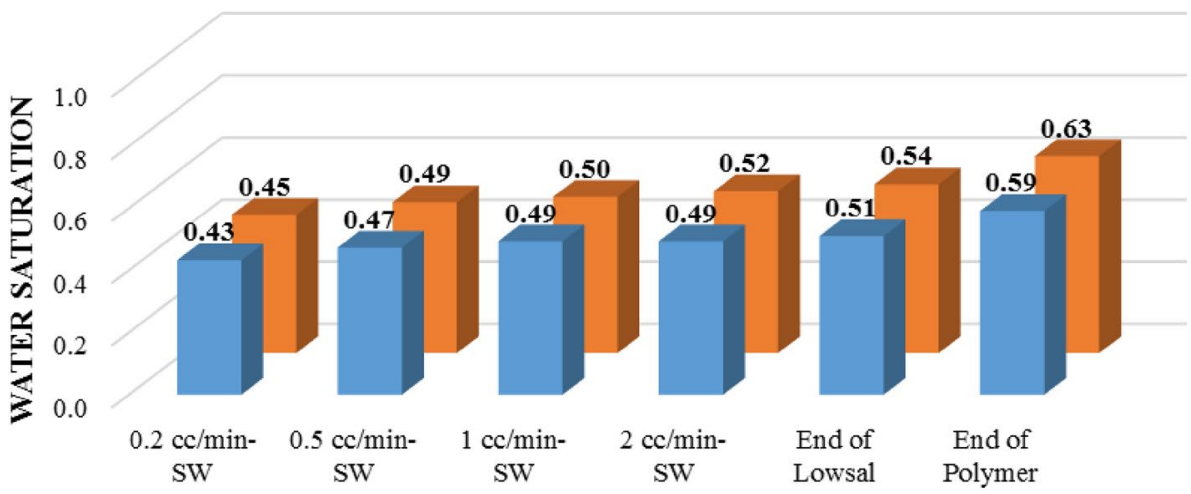

INJECTION SCENARIOS

=Voumetric Data $\quad$ ISSM Data

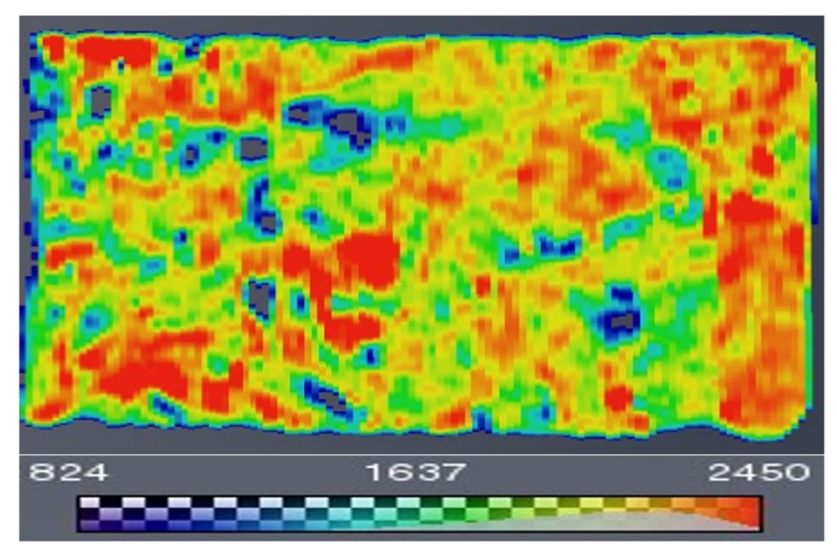

Fig. $12 \mathrm{CT}$ image showing the $S_{\mathrm{OR}}$, heterogeneity, and vugs in the core plug used for Exp. 2. High CT number indicating high density

salinity water flooding only minimized the capillary end effect as a result of the high flow rate. The in situ saturation monitoring profiles correlates with the volumetric production data as well as CT image (Fig. 12) which shows poor oil displacement along the core length due to high heterogeneity as well as vugs. Thus, lack of additional oil recovery during polymer flooding compared to Exp. 1 could be due to the heterogeneity and vugs in the core plug. Comparison between volumetric production data and ISSM was done and is shown in Fig. 11.

Table 5 summarizes the results from Exp. 2 experiment. Similarly, the core was CT scanned to have a clear image at residual oil saturation. As expected, significant amount of oil was left unswept in the core due to poor oil sweep and can be seen from Fig. 12.

\section{Core flooding experiment 3 (Exp. 3)}

The average counts at $100 \%$ oil saturation was 42,400 . Brine absolute permeability and thus $100 \%$ water saturation scan was measured. The average counts at $100 \%$ brine saturation was 74,845 . Finally, the scans representing $S_{w i}$ were taken
Table 5 Summary of major parameters from the second core flooding experiment

\begin{tabular}{ll}
\hline Core ID & Exp. 2 \\
\hline Mobility ratio during WF & 2.21 \\
Mobility ration during PF & 1.75 \\
Resistance factor RF at $2.0 \mathrm{cc} / \mathrm{min}$ & 1.99 \\
Residual resistance factor at $2.0 \mathrm{cc} / \mathrm{min}$ & 1.40 \\
Water flooding oil recovery $(\%)$ & 51 \\
Additional oil recovery due to polymer (\%) & 8 \\
Total oil recovery $(\%)$ & 59 \\
\hline
\end{tabular}

after ageing and was 45,630 and initial water saturation was calculated to be $12.31 \%$.

Oil recovery was initiated after measuring oil effective permeability at post ageing stage. Initially, seawater was injected into the core for $20 \mathrm{~h}$ until no more oil production. Then, $0.25 * \mathrm{SW}$ was injected for about $7 \mathrm{~h}$ to precondition the core sample and to see if low salinity water flooding could recover more oil. Finally, 3,000 ppm of polymer in $0.25 * \mathrm{SW}$ was injected for another $7 \mathrm{~h}$ before switching to postflush water flooding.

With SW flooding, the cumulative oil recovery was 65\%. After seawater was injected at different flow rates (from 0.2 to $2.0 \mathrm{cc} / \mathrm{min}$ ), the fluid was switched to low salinity brine and additional $1.3 \%$ was recovered. The same flow rates were repeated during low salinity water flooding. Similarly, there was no production at the initial flow rates of $0.2,0.5$, and $1.0 \mathrm{cc} / \mathrm{min}$. Thus, oil recovery from low salinity water flooding was produced during the $2.0 \mathrm{cc} / \mathrm{min}$ alone as shown in Fig. 13. These results are in accordance with the previous literature who found that low-salinity water flooding could not recover additional oil after seawater flooding in strong water-wet cores (Shaker and Skauge 2013). Then, 9\% additional oil was recovered during polymer flooding. Because of the low permeability, polymer was only injected at $0.2 \mathrm{cc} / \mathrm{min}$ to avoid core damage. High resistance factor 
Fig. 13 Oil recovery factor and differential pressure vs PV injected during oil recovery of Exp. 3 based on volumetric data

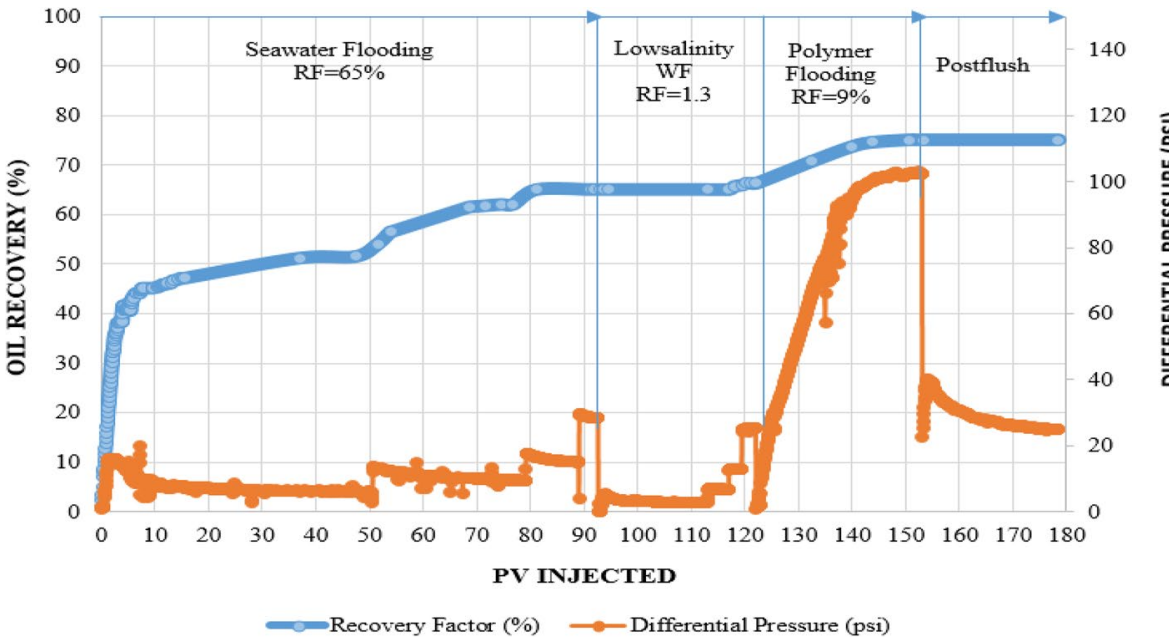

Low salinity water flooding was initiated after production from SW is negligible. As mentioned earlier, the same flow rates used during SW flooding were repeated as well for low salinity water flooding. Small amount of oil (water saturation increased to 0.72 ) was produced as can be seen from the figure. Finally, polymer was injected after the low salinity water flooding. A significant amount of oil was produced from polymer flooding. The average water saturation increased from 0.72 to 0.79 . In addition, the error margin was found to be less as shown in Fig. 15.

Based on the ISSM profiles, it can be seen that oil production from the low-salinity water flooding was not truly caused by low-salinity brine, rather the additional oil production could be due to the following reasons:

- The additional oil production by low salinity only came during the highest flow rate $(2.0 \mathrm{cc} / \mathrm{min})$ and nothing was produced during the low flow rates. At $2.0 \mathrm{cc} / \mathrm{min}$ of lowsalinity water injection, the viscous force (thus, pressure
Fig. 14 ISSM showing the effect of polymer flooding on oil recovery during Exp. 3

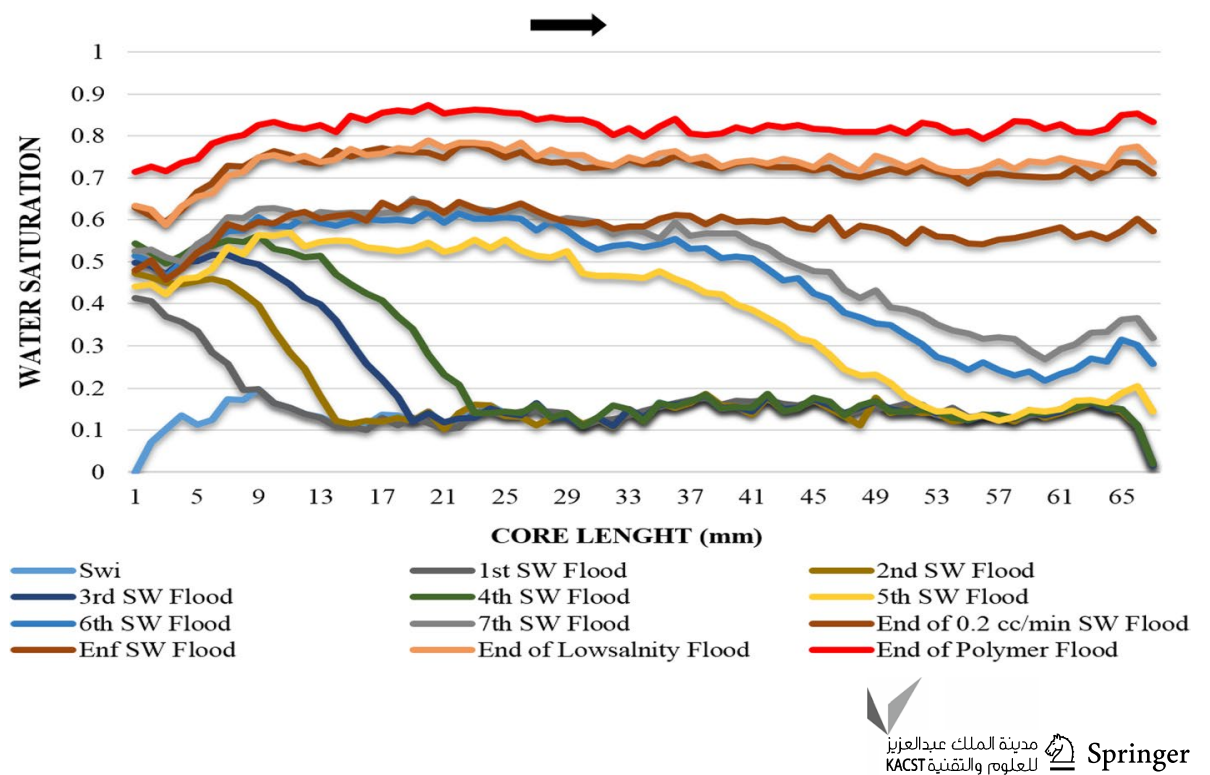


Fig. 15 Comparison between volumetric production data and in situ saturation monitoring data during Exp. 3

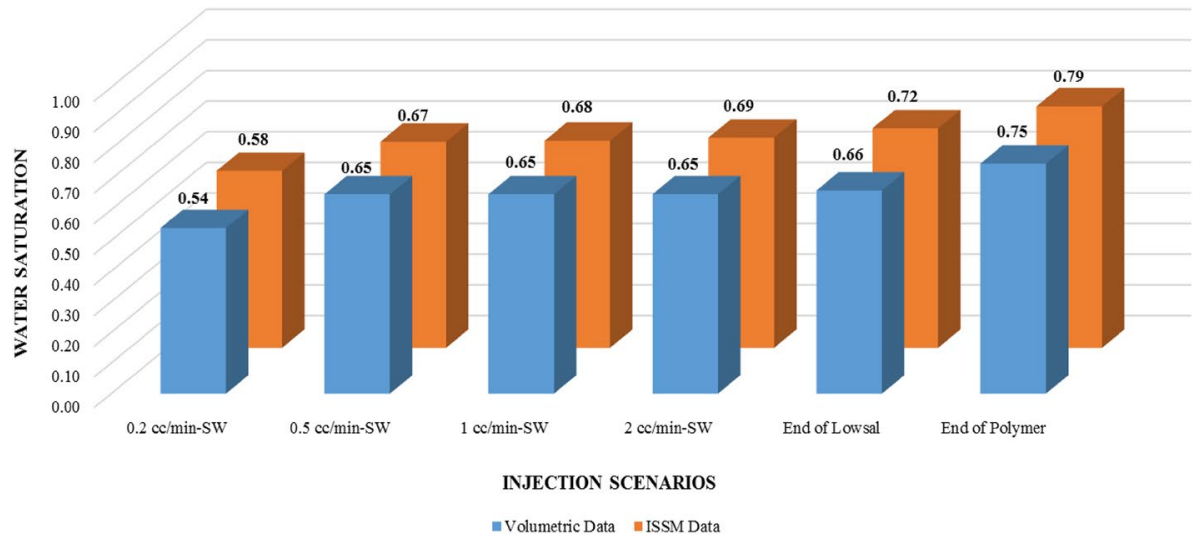

drop) is almost equal to that of SW injection at the same flow rate.

- It can be seen that the saturation profile during low-salinity water flooding only slightly changed in end part of the core (from $45 \mathrm{~mm}$ to end of the core). This also indicates that the production was due to capillary end effect that was minimized because of the high flow rate used at that particular time of injection.

- Polymer increased the oil recovery across the whole length of the core which means that the polymer was able to increase the sweep efficiency. The polymer was only injected at $0.2 \mathrm{cc} / \mathrm{min}$ because of high pressure drop due to low permeability of the core and retention occurrence

In summary, even as only $0.2 \mathrm{cc} / \mathrm{min}$ was during polymer flooding, an additional $9 \%$ of oil was recovered which was more as compared to the previous core floods. Hence, more oil could have been recovered at higher bump rates. The effectiveness of the polymer flooding was due to low salinity water preconditioning which resulted in higher solution viscosity and thus better mobility ratio reduction. Moreover, there was better oil sweep as compared to Exp. 2 as a result of less heterogeneity in the core plug. This was confirmed from both in situ saturation profiles and the CT image. CT scan image showed that the core is less vuggy compared to previous cores (Exp.1 and Exp.2) as can be seen from Fig. 16. Table 6 summarizes the main parameters and results from Exp. 3. As a result, there was better sweep of oil compared to previous experiments.

\section{Conclusions}

- Difficulties in the application of polymer flooding on HTHS reservoir can be overcome by injecting slugs of low-salinity brines before initiation of polymer flooding to precondition the high salinity.

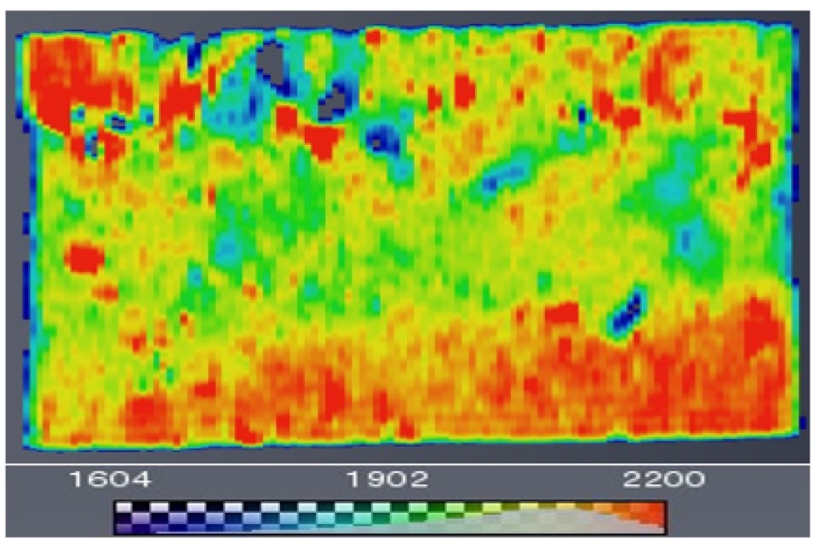

Fig. 16 Scanned image of Exp. 3 at $S_{\mathrm{OR}}$ showing heterogeneity and vugs along the core. The red color in the image represents high CT number and hence high density

Table 6 Summary of major results from third core flooding experiment

\begin{tabular}{ll}
\hline Core ID & Exp. 3 \\
\hline Mobility ratio during WF & 3.28 \\
Mobility ratio during PF & 0.06 \\
Absolute brine permeability (md) & 10 \\
Resistance factor at 0.2 cc/min & 36 \\
Residual resistance factor & 8.9 \\
Water flooding oil recovery (\%) & 66.3 \\
Additional oil recovery due to polymer (\%) & 9 \\
\hline
\end{tabular}

- The polymer used in this study was successful in improving the mobility ratio resulting in better sweep efficiency and hence producing more oil.

- It was found that, there was no significant oil production during low-salinity water flooding. The little production was due to capillary end effect that was minimized by the high flow rates. This was confirmed from the in situ saturation profiles. However, low salinity water flooding 
resulted in the injection of polymer solutions with higher viscosities through preconditioning of the high-salinity formation.

- ISSM data from the linear X-ray confirmed the accuracy of the result during oil recovery. The difference between the volumetric production data and the ISSM is within $5 \%$.

- ISSM data helped in identifying the heterogeneity level in the cores, as well as capillary end effect.

- Resistance factor and residual resistance factor were found to be lower in high permeability core compared to the tight cores. The resistance factor was decreasing with increase in flow rates in high permeability core and increasing with increase flow rates in tight cores.

- The effective in situ viscosity was also found to be dependent on permeability. Shear thinning behavior was observed in high permeability sample while a shear thickening behavior was seen in low permeability core.

Acknowledgements The authors acknowledge The Petroleum Institute, a part of Khalifa University of Science and Technology for financing this research and ADNOC for providing core samples and formation water composition. The authors also would like to thank SNF for providing the polymer sample.

Open Access This article is distributed under the terms of the Creative Commons Attribution 4.0 International License (http://creativeco mmons.org/licenses/by/4.0/), which permits unrestricted use, distribution, and reproduction in any medium, provided you give appropriate credit to the original author(s) and the source, provide a link to the Creative Commons license, and indicate if changes were made.

\section{References}

Agi A, Junin R, Gbonhinbor J, Onyekonwu M (2018) Natural polymer flow behaviour in porous media for enhanced oil recovery applications: a review. J Pet Explor Prod Technol. https://doi.org/10.1007/ s13202-018-0434-7

Algharaib M, Alajmi A, Gharbi R (2014) Improving polymer flood performance in high salinity reservoirs. J Petrol Sci Eng 115:17-23

Almansour AO, AlQuraishi AA, AlHussinan SN, AlYami HQ (2017) Efficiency of enhanced oil recovery using polymer-augmented low salinity flooding. J Pet Explor Prod Technol 7:1149-1158

AlSofi AM, Wang J, Leng Z, Abbad M, Kaidar ZF (2017) Assessment of polymer interactions with carbonate rocks and implications for EOR applications. In: SPE Kingdom of Saudi Arabia annual technical symposium and exhibition, SPE 188086-MS. Society of Petroleum Engineers

API R 63 (1990) Recommended practices for evaluation of polymers used in enhanced oil recovery operations. API, Washington, DC

Bennetzen MV, Gilani SFH, Mogensen K, Ghozali M, Bounoua N (2014) Successful polymer flooding of low-permeability, oil-wet, carbonate reservoir cores. In: Abu Dhabi international petroleum exhibition and conference, Society of Petroleum Engineers
Cannella W, Huh C, Seright R (1988) Prediction of xanthan rheology in porous media. In: SPE annual technical conference and exhibition. Society of Petroleum Engineers

Delaplace P, Delamaide E, Roggero F, Renard G (2013) History matching of a successful polymer flood pilot in the Pelican Lake heavy oil field (Canada). In: SPE annual technical conference and exhibition, Society of Petroleum Engineers

Gaillard N, Giovannetti B, Favero C, Caritey J-P, Dupuis G, Zaitoun A (2014) New water soluble anionic NVP acrylamide terpolymers for use in harsh EOR conditions. In: SPE improved oil recovery symposium, Society of Petroleum Engineers, Society of Petroleum Engineers

Gaillard N, Giovannetti B, Leblanc T, Thomas A, Braun O, Favero C (2015) Selection of customized polymers to enhance oil recovery from high temperature reservoirs. In: SPE Latin American and Caribbean petroleum engineering conference. Society of Petroleum Engineers

Gao C (2013) Viscosity of partially hydrolyzed polyacrylamide under shearing and heat. J Pet Explor Prod Technol 3:203-206

Green DW, Willhite GP (1998) Enhanced oil recovery, vol 6. Henry L. Doherty Memorial Fund of AIME, Society of Petroleum Engineers, Richardson

Han M, Zhou X, Fuseni AB, Al-Zahrani BH, AlSofi AM (2012) Laboratory investigation of the injectivity of sulfonated polyacrylamide solutions into carbonate reservoir rocks. In: SPE EOR conference at oil and gas West Asia, Society of Petroleum Engineers

Han M, Fuseni A, Zahrani B, Wang J (2014) Laboratory study on polymers for chemical flooding in carbonate reservoirs. In: SPE EOR Conference at Oil and Gas West Asia, 2014. Society of Petroleum Engineers

Hashmet MR, AlSumaiti AM, Qaiser Y, AlAmeri SW (2017a) Laboratory investigation and simulation modeling of polymer flooding in high-temperature, high-salinity carbonate reservoirs. Energy Fuels 31:13454-13465

Hashmet MR, Qaiser Y, Mathew ES, AlAmeri W, AlSumaiti AM (2017b) Injection of polymer for improved sweep efficiency in high temperature high salinity carbonate reservoirs: linear X-ray aided flood front monitoring. In: SPE Kingdom of Saudi Arabia Annual Technical Symposium and Exhibition, Society of Petroleum Engineers

Khorsandi S, Qiao C, Johns RT (2016) Displacement efficiency for low salinity polymer flooding including wettability alteration. In: SPE improved oil recovery conference, Society of Petroleum Engineers

Khorsandi S, Qiao C, Johns RT (2017) Displacement efficiency for low-salinity polymer flooding including wettability alteration. SPE J 22:417-430

Leblanc T, Braun O, Thomas A, Divers T, Gaillard N, Favero C (2015) Rheological properties of stimuli-responsive polymers in solution to improve the salinity and temperature performances of polymerbased chemical enhanced oil recovery technologies. In: SPE Asia Pacific enhanced oil recovery conference, Society of Petroleum Engineers

Levitt D, Klimenko A, Jouenne S, Chamerois M, Bourrel M (2013) Overcoming design challenges of chemical EOR in high-temperature, high salinity carbonates. In: SPE Middle East oil and gas show and conference, 2013. Society of Petroleum Engineers

Nasr-El-Din H, Taylor K (1996) Rheology of water-soluble polymers used for improved oil recovery. In: Cheremisinoff NP (ed) Advances in engineering fluid mechanics: multiphase reactor and polymerization system hydrodynamics. Elsevier, Amsterdam, pp 615-668

Quadri SMR, Shoaib M, AlSumaiti AM, Alhassan SM (2015) Screening of polymers for EOR in high temperature, high salinity and carbonate reservoir conditions. In: International petroleum technology conference 
RezaeiDoust A, Puntervold T, Austad T (2011) Chemical verification of the EOR mechanism by using low saline/smart water in sandstone. Energy Fuels 25:2151-2162

Salmo IC, Pettersen $\varnothing$, Skauge A (2017) Polymer flooding at an adverse mobility ratio: acceleration of oil production by crossflow into water channels. Energy Fuels 31:5948-5958

Samanta A, Bera A, Ojha K, Mandal A (2010) Effects of alkali, salts, and surfactant on rheological behavior of partially hydrolyzed polyacrylamide solutions. J Chem Eng Data 55:4315-4322

Seright RS, Seheult JM, Talashek T (2008) Injectivity characteristics of EOR polymers. In: SPE annual technical conference and exhibition. Society of Petroleum Engineers

Seright RS, Fan T, Wavrik K, Balaban RDC (2011) New insights into polymer rheology in porous media. SPE J 16:35-42

Shaker B, Skauge A (2013) Enhanced oil recovery (EOR) by combined low salinity water/polymer flooding. Energy Fuels 27:1223-1235

Sheng JJ (2017) Critical review of alkaline-polymer flooding. J Pet Explor Prod Technol 7:147-153

Sheng JJ, Leonhardt B, Azri N (2015) Status of polymer-flooding technology. J Can Pet Technol 54:116-126

Sorbie KS (2013) Polymer-improved oil recovery. Springer, Berlin

Unsal E, Ten Berge ABGM, Wever DAZ (2018) Low salinity polymer flooding: lower polymer retention and improved injectivity. J Pet Sci Eng 163:671-682

Vermolen E, Van Haasterecht MJ, Masalmeh SK, Faber MJ, Boersma DM, Gruenenfelder MA (2011) Pushing the envelope for polymer flooding towards high-temperature and high-salinity reservoirs with polyacrylamide based ter-polymers. In: SPE Middle East oil and gas show and conference, Society of Petroleum Engineers
Vermolen EC, Pingo-Almada M, Wassing BM, Ligthelm DJ, Masalmeh SK (2014) Low-salinity polymer flooding: improving polymer flooding technical feasibility and economics by using low-salinity make-up brine. In: IPTC 2014: international petroleum technology conference

Wang D, Han P, Shao Z, Hou W, Seright RS (2008) Sweep-improvement options for the Daqing oil field. SPE Reserv Eval Eng $11: 18-26$

Wei B, Romero-Zerón L, Rodrigue D (2014) Oil displacement mechanisms of viscoelastic polymers in enhanced oil recovery (EOR): a review. J Pet Explor Prod Technol 4:113-121

Wever D, Picchioni F, Broekhuis A (2011) Polymers for enhanced oil recovery: a paradigm for structure-property relationship in aqueous solution. Prog Polym Sci 36:1558-1628

Zaitoun A, Kohler N (1988) Two-phase flow through porous media: effect of an adsorbed polymer layer. In: SPE annual technical conference and exhibition, Society of Petroleum Engineers

Zaitoun A, Makakou P, Blin N, Al-Maamari RS, Al-Hashmi A-AR, Abdel-Goad M (2012) Shear stability of EOR polymers. Spe J 17:335-339

Zhang S, She Y, Gu Y (2011) Evaluation of polymers as direct thickeners for $\mathrm{CO}_{2}$ enhanced oil recovery. J Chem Eng Data 56:1069-1079

Publisher's Note Springer Nature remains neutral with regard to jurisdictional claims in published maps and institutional affiliations. 